\title{
Fluorescent Molecular Beacons Mimicking RNA Secondary Structures to Study RNA Chaperone Activity
}

\author{
Pilar Menendez-Gil, Carlos J. Caballero, Cristina Solano, \\ and Alejandro Toledo-Arana
}

\begin{abstract}
Molecular beacons (MBs) are oligonucleotide probes with a hairpin-like structure that are typically labelled at the $5^{\prime}$ and $3^{\prime}$ ends with a fluorophore and a quencher dye, respectively. The conformation of the MB acts as a switch for fluorescence emission. When the fluorophore is in close proximity to the quencher, fluorescence emission cannot be detected, meaning that the switch is in an OFF state. However, if the $\mathrm{MB}$ structure is modified, separating the fluorophore from the quencher, the switch turns $\mathrm{ON}$ allowing fluorescence emission. This property has been extensively used for a wide variety of applications including real-time PCR reactions, study of protein-DNA interactions, and identification of conformational changes in RNA structures. Here, we describe a protocol based on the MB technology to measure the RNA unfolding capacities of the CspA RNA chaperone from Staphylococcus aureus. This method, with slight variations, may also be applied for testing the activity of other RNA chaperones, RNA helicases, or ribonucleases.
\end{abstract}

Key words RNA, Chaperone, RNA-binding protein, Hairpin, Stem loop, Molecular beacon, Fluorescein, Quencher, FAM

\section{Introduction}

Molecular beacons (MBs) are oligonucleotide probes commonly used to target DNA for real-time monitoring of polymerase chain reactions (RT-PCRs). The central nucleotides of the MB are complementary to a specific DNA (or RNA) target and do not base pair with one another, while the five to seven nucleotides at each terminus are complementary to each other, creating a hairpin-like conformation (Fig. la). Since the $5^{\prime}$ and $3^{\prime}$ ends are labelled with a fluorophore and a quencher, respectively, the $\mathrm{MB}$ acts as a switch. In their native conformation, the extremes are close enough for the quencher to prevent fluorescent emission from the fluorophore (switch OFF). When the MB hybridizes with its specific target, its native structure is disrupted, and both dye molecules fall apart from 
A

Native configuration

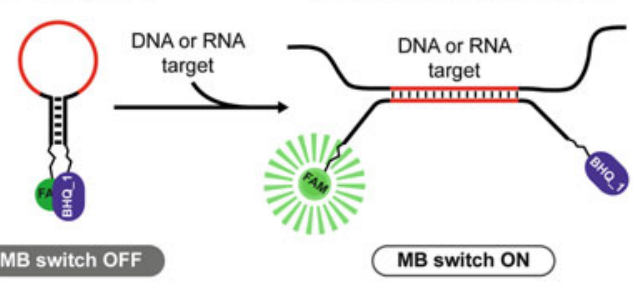

C

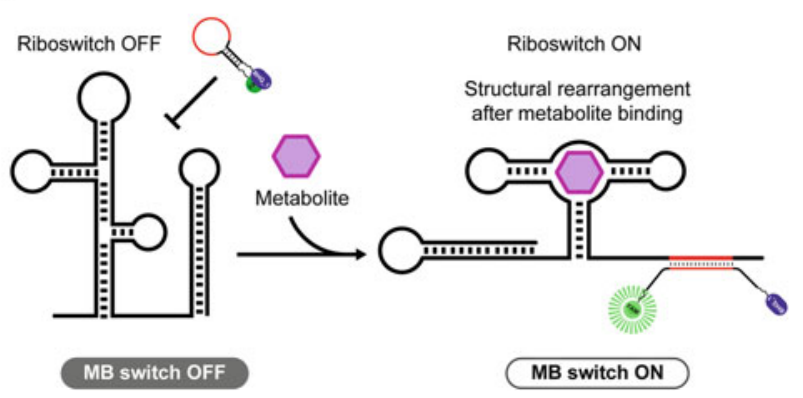

B

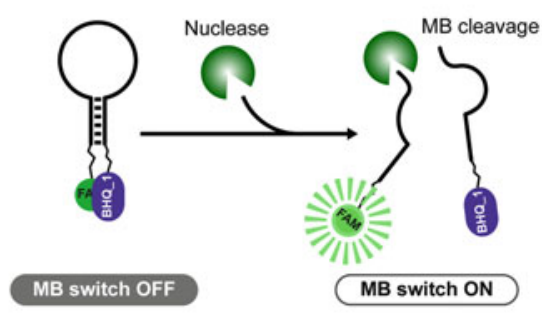

D

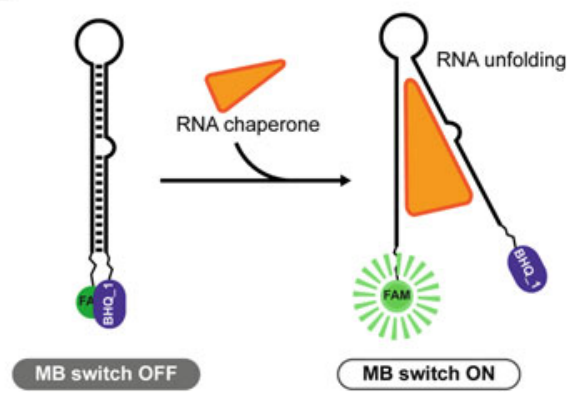

Fig. 1 Examples of different MB designs dedicated to (a) quantifying specific DNA or RNA molecules, (b) analyzing the single-stranded DNA cleavage by specific nucleases [4], (c) studying the structural changes on ribozymes and riboswitches $[5,6]$, or (d) determining the RNA chaperone activity on hairpin-like structures by cold shock proteins (CSPs) [7-9]. In all cases, the MB switch turns on when the fluorophore (FAM) folds away of the quencher (BHQ_1) due to the base-pairing of the MB with its specific target (a, $\mathbf{c})$ or to the MB cleavage or unfolding by the activity of an RNA-binding protein $(\mathbf{b}, \mathbf{d})$

each other, allowing fluorescence emission (switch ON) (Fig. la). Since MBs tolerate very versatile designs, they have been used for various applications $[1,2]$. Molecular biologists have taken advantage of their potential for studying different mechanisms such as protein-DNA interactions [3], single-stranded DNA cleavage by specific nucleases (Fig. 1b) [4], and structural changes on ribozymes and riboswitches (Fig. 1c) [5, 6]. In this last case, RNA conformational changes have been determined by the use of MBs that target specific RNA regions that become free for hybridization. This usually occurs after binding of the metabolite, which induces the subsequent RNA structural change on the ribozyme or riboswitch (Fig. 1c) [5, 6]. Thus, only when the MB is bound to its RNA target, the probe structure unfolds and becomes fluorescent. On the other hand, in order to study RNA chaperone activity, a more direct approach by using a $\mathrm{MB}$ that mimics the regulatory RNA hairpin targeted by a specific RNA-binding protein (RBP) has been adopted $[7,8]$. This strategy assumes that binding of the RNA chaperone to the $\mathrm{MB}$ may cause a similar RNA conformational rearrangement to the one occurring on the native RNA. Therefore, the MB may act as a direct reporter of its own structural rearrangement (Fig. 1d). We choose this approach to demonstrate that the 


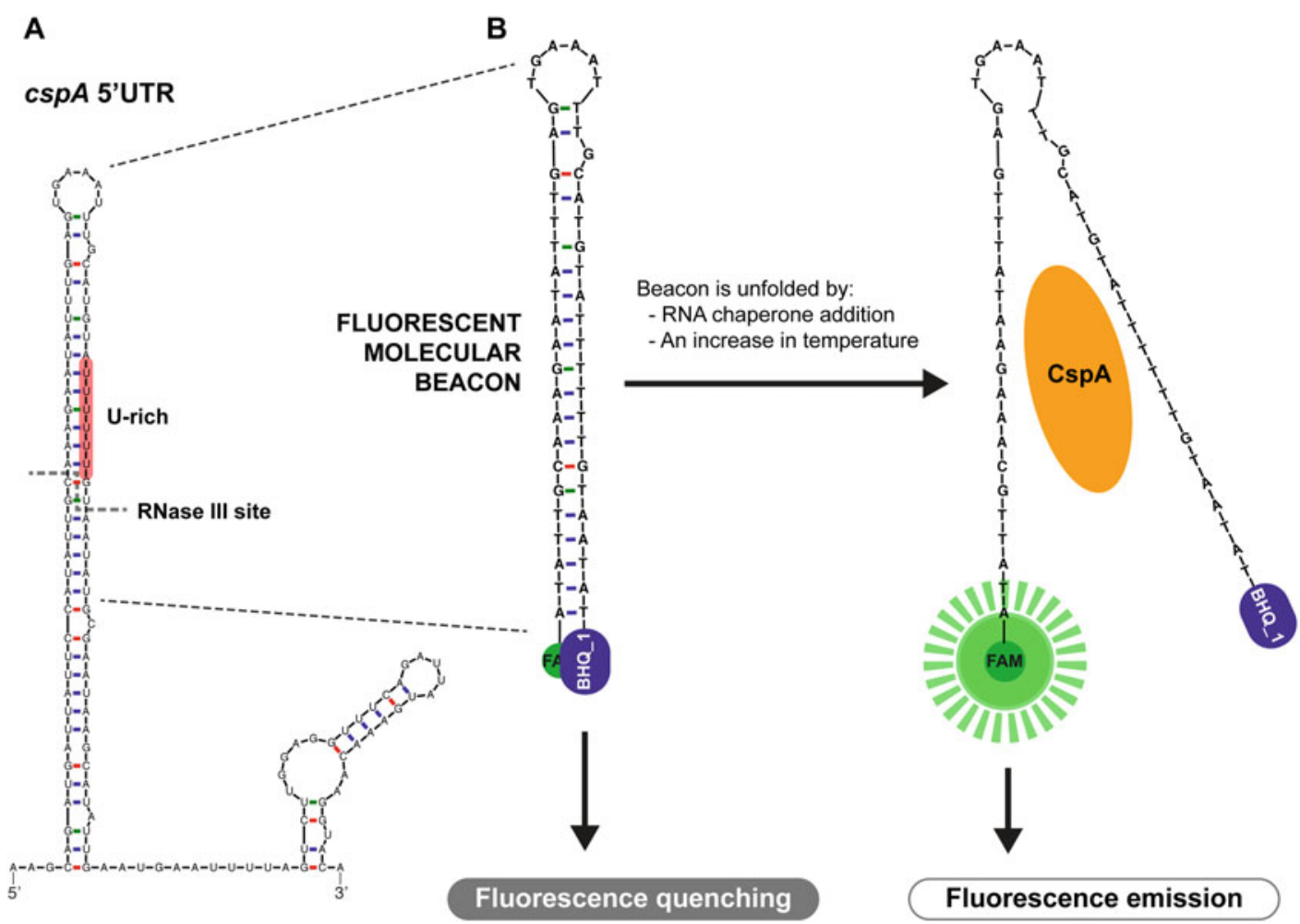

Fig. 2 Molecular beacon (MB) design to study the CspA RNA chaperone activity on the RNA hairpin structure of the $\operatorname{cspA}$ mRNA [9]. (a) The proposed RNA structure for the $5^{\prime} U T R$ of $\operatorname{cspA}$ is shown [10]. The U-rich motif required for CspA interaction is highlighted in red. (b) The MB consisted of a 49-mer ssDNA oligonucleotide labelled with the FAM fluorophore and the BHQ_1 quencher at its $5^{\prime}$ and $3^{\prime}$ ends, respectively [9]

RNA chaperone CspA of Staphylococcus aureus unfolds the RNA hairpin present in the $5^{\prime} \mathrm{UTR}$ of its own mRNA [9] (Fig. 2a). This hairpin $(\Delta G=-24.60 \mathrm{kcal} / \mathrm{mol})$ is cleaved by endoribonuclease III (RNase III) mainly at position G-53, generating a shorter $c s p A$ mRNA version that is more efficiently translated than the unprocessed mRNA [10]. CspA would repress its own expression by unfolding the hairpin and thus antagonize the function of RNase III [9].

Specifically, we designed a MB that comprised a 49-mer ssDNA oligonucleotide, which included the central functional sequence of the $\operatorname{csp} A 5^{\prime}$ UTR hairpin $(\Delta G=-13.70 \mathrm{kcal} / \mathrm{mol})$. A molecule of fluorescein (FAM) and a Black Hole Quencher (BHQ_l) were attached to the $5^{\prime}$ and $3^{\prime}$ ends, respectively (Fig. $2 \mathrm{~b}$ ). In the native $\mathrm{MB}$ conformation, BHQ_l efficiently quenched the fluorescence from FAM, indicating that the designed MB accurately mimicked the $\operatorname{csp} A 5^{\prime} \mathrm{UTR}$ hairpin. In contrast, when the MB structure was disrupted (separating FAM from BHQ_1) either by the presence of the RNA chaperone CspA or by an increase in the temperature of incubation, fluorescence emission was registered. The folded 


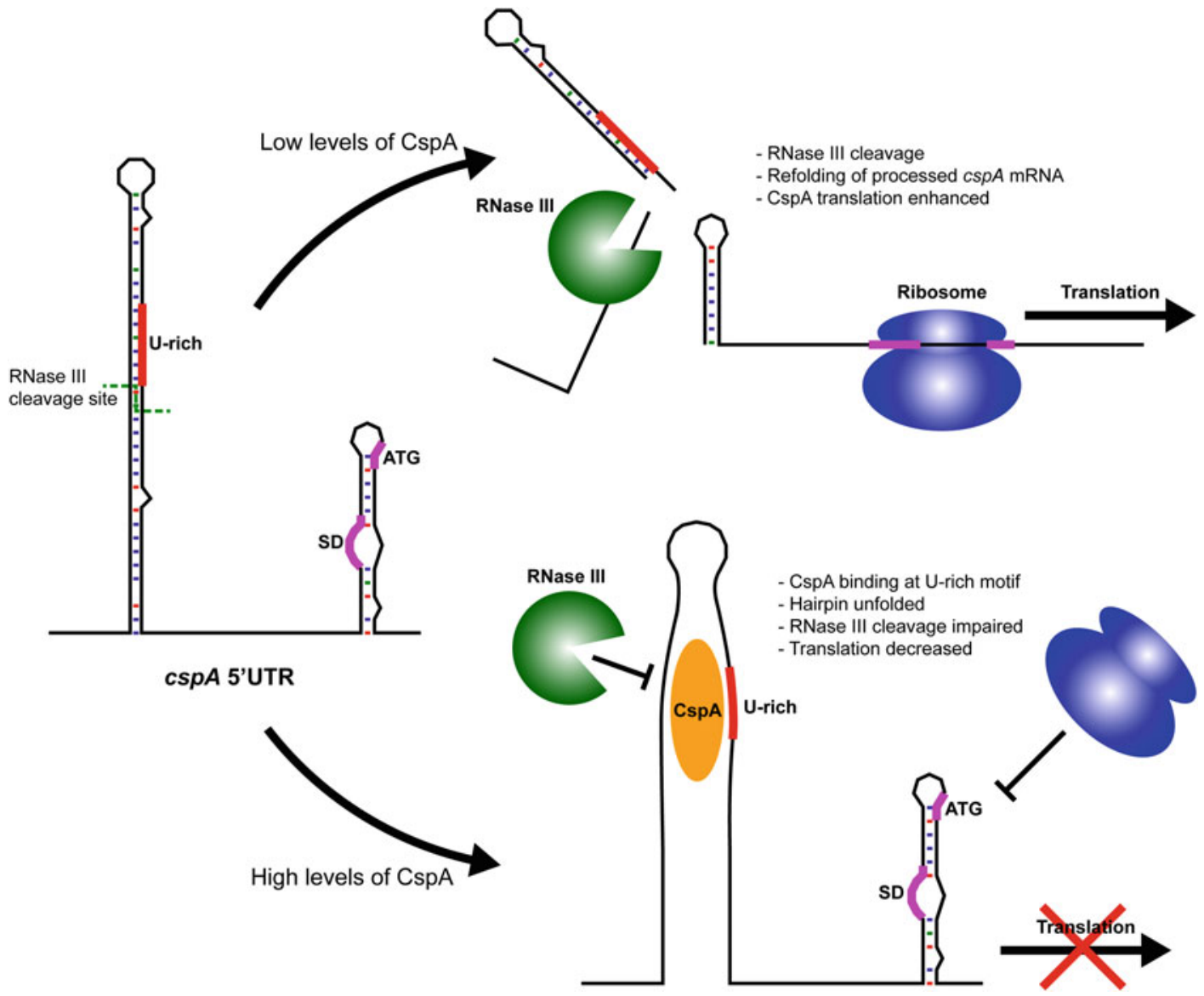

Fig. 3 Schematic representation of the putative auto-regulatory mechanism modulating CspA expression as previously described by Caballero and colleagues [9]. The $5^{\prime}$ UTR of the $\operatorname{cspA}$ mRNA forms a hairpin structure that is cleaved by RNase III to enhance CspA translation when CspA levels are Iow [10]. When the concentration of CspA inside the cell is high, the protein is able to interact with the hairpin structure through a U-rich motif and unfold it. As a consequence, the $\operatorname{cspA}$ mRNA is not processed by RNase III and CspA translation is decreased

conformation of the $\mathrm{MB}$ could be efficiently restored (indicated by the ceasing of fluorescence emission) either by adding Proteinase $\mathrm{K}$, which eliminated the chaperone activity by degrading CspA, or by decreasing the temperature of incubation. The specificity of CspA on the designed MB system was verified by the incubation of the $\mathrm{MB}$ with an unrelated protein.

This strategy allowed us to demonstrate that CspA unfolded the regulatory hairpin located at the $\operatorname{csp} A 5^{\prime} \mathrm{UTR}$ and, thus, interfered with $\operatorname{csp} A$ mRNA processing by RNase III. When CspA levels were low, the $\operatorname{cs} p A 5^{\prime} \mathrm{UTR}$ RNA hairpin was targeted and cleaved by RNase III. The resulting processed mRNA suffered a conformational change that favored CspA translation [10]. When CspA levels rose, CspA decreased its own expression by unfolding the $\operatorname{csp} A$ 5'UTR RNA hairpin to avoid RNase III cleavage [9] (Fig. 3). 
Here, we describe in detail the different steps that should be followed to determine the RNA folding rearrangements caused by the binding of any RBP by using a MB that mimics a natural target (whose synthesis could be ordered from a regular oligonucleotide supplier company). The protocol requires commonly available equipment at a molecular biology research center. It is noteworthy that, with slight modifications, this protocol may be adapted to test (1) any DNA or RNA folding structure that allows close proximity of BHQ_1 to FAM and that provides enough separation between them when disrupted; (2) the activity of RBPs such as RNA chaperones, RNA helicases and ribonucleases that target and/or process hairpin-like structures; and (3) the function of small regulatory RNAs that produce conformational changes on hairpin-like structures of their mRNA targets.

\section{Materials}

\subsection{Purification of the Recombinant RNA Chaperone CspA}

2.1.1 Growth of Bacteria Expressing GST-CspA Fusion Protein
Prepare all solutions using ultrapure water (prepared by purifying deionized water to reach a sensitivity of at least $18 \mathrm{M} \Omega$ at $25^{\circ} \mathrm{C}$ ) and analytical grade reagents for use in molecular biology. Store solutions at room temperature unless stated otherwise. Follow safety and waste disposal regulations when handling harmful products accordingly.

1. E. coli BL21 (DE3) harboring pGEX-6P-2::cspA (see Note 1).

2. Sterile material for bacterial growth: 10-, 100- and $1000-\mu \mathrm{L}$ pipette tips, test tubes, 2-L Erlenmeyer flasks, graduated cylinders, 250-mL centrifuge tubes, petri dishes, 1.5-mL Eppendorf tubes.

3. $100 \mathrm{mg} / \mathrm{mL}$ ampicillin stock solution sterilized by filtration. Store at $-20{ }^{\circ} \mathrm{C}$.

4. $40 \%$ Glucose solution sterilized by filtration.

5. Luria Bertani (LB) agar plates supplemented with $100 \mu \mathrm{g} / \mathrm{mL}$ ampicillin.

6. Microbiological incubator at $37^{\circ} \mathrm{C}$.

7. Luria Bertani (LB) medium sterilized by autoclave and supplemented with glucose and ampicillin to a final concentration of $1 \%$ and $100 \mu \mathrm{g} / \mathrm{mL}$, respectively.

8. Shaking incubator at $37^{\circ} \mathrm{C}$ and 200 r.p.m.

9. Spectrophotometer.

10. Centrifuge with rotor for Eppendorf tubes.

11. $200 \mathrm{mg} / \mathrm{mL}$ Isopropyl- $\beta$-D-1-thiogalactopyranoside (IPTG) stock solution, sterilized by filtration. Store at $-20{ }^{\circ} \mathrm{C}$. 
2.1.2 Bacterial Cell Lysis and Recovery of Total Protein Crude Extract
2.1.3 Purification of Recombinant CspA from Total Protein Crude Extracts
12. Refrigerated centrifuge with rotor for $250-\mathrm{mL}$ centrifuge flasks.

13. Phosphate buffered saline (PBS): $\mathrm{pH} 7.3,140 \mathrm{mM} \mathrm{NaCl}$, $2.7 \mathrm{mM} \mathrm{KCl}, 10 \mathrm{mM} \mathrm{Na} \mathrm{HPO}_{4}, 1.8 \mathrm{mM} \mathrm{KH}_{2} \mathrm{PO}_{4}$ sterilized by autoclave.

1. Sterile $15-\mathrm{mL}$ and $50-\mathrm{mL}$ conical tubes.

2. Sterile PBS pH 7.3 (see item 13 in Subheading 2.1.1).

3. $50 \mathrm{mg} / \mathrm{mL}$ Lysozyme stock solution sterilized by filtration. Store at $-20{ }^{\circ} \mathrm{C}$.

4. $10 \mathrm{mg} / \mathrm{mL}$ RNase A stock solution. Store at $-20^{\circ} \mathrm{C}$.

5. $100 \mathrm{mM}$ Phenylmethanesulfonyl fluoride (PMSF) stock solution prepared in isopropanol. Store at $-20{ }^{\circ} \mathrm{C}($ see Note 2$)$.

6. Shaking incubator at $30^{\circ} \mathrm{C}$ and 200 r.p.m.

7. Branson sonifier 250 with microtip.

8. Centrifuge with a rotor for 50-mL tubes, which allows centrifugation at $16,000 \times \mathfrak{g}$.

9. High speed centrifuge tubes.

10. $5 \mathrm{mg} / \mathrm{mL}$ DNase I stock solution prepared by dissolving DNase I powder in $0.15 \mathrm{M} \mathrm{NaCl}$.

11. $0.45 \mu \mathrm{m}$ filters and 1.5-mL Eppendorf tubes.

12. $12 \%$ SDS-polyacrylamide gels.

13. $6 \times$ Sample buffer: $375 \mathrm{mM}$ Tris- $\mathrm{HCl} \mathrm{pH} 6.8,9 \%$ SDS, $50 \%$ glycerol, $9 \% \beta$-mercaptoethanol and $0.03 \%$ bromophenol blue. Store at $-20{ }^{\circ} \mathrm{C}$.

14. Tris-glycine running buffer: $25 \mathrm{mM}$ Tris, $192 \mathrm{mM}$ glycine, $0.1 \%$ SDS.

15. Protein molecular weight marker. Store at $-20^{\circ} \mathrm{C}$.

16. Heating block.

17. Electrophoresis chamber for polyacrylamide gels.

18. Power supply.

19. Coomassie brilliant blue R250 solution.

20. Orbital shaker.

21. Destaining solution: $40 \%$ ethanol and $10 \%$ acetic acid in water.

22 . Fixation solution: $10 \%$ ethanol and $3 \%$ glycerol in water.

1. AKTAprime plus chromatography system.

2. GSTrap FF 5-mL column.

3. GSTrap FF 1-mL column.

4. HiPrep 16/60 Sephacryl S-100 HR column. 
5. Ultrapure water, sterilized by autoclave and degassed.

6. $20 \%$ ethanol solution sterilized by autoclave and degassed.

7. Binding Buffer: degassed sterile PBS pH 7.3 (see item 13 in Subheading 2.1.1).

8. PreScission Protease buffer: $50 \mathrm{mM}$ Tris- $\mathrm{HCl} \mathrm{pH}$ 7, $150 \mathrm{mM}$ $\mathrm{NaCl}, 1 \mathrm{mM}$ EDTA, $1 \mathrm{mM}$ DTT sterilized by autoclave and degassed.

9. PreScission Protease.

10. PreScission Protease mix: mix $100 \mu \mathrm{L}$ (200 units) of PreScission Protease with $4.9 \mathrm{~mL}$ of PreScission Protease buffer at $4{ }^{\circ} \mathrm{C}$.

11. 5-mL syringe with Luer tip.

12. 1.5-mL Eppendorf tubes and 15-mL conical tubes.

13. Elution buffer: $50 \mathrm{mM}$ Tris- $\mathrm{HCl} \mathrm{pH} 8,10 \mathrm{mM}$ reduced glutathione sterilized by autoclave and degassed.

14. Gel Filtration buffer: $20 \mathrm{mM}$ Tris- $\mathrm{HCl}$ pH 7.4, $500 \mathrm{mM} \mathrm{NaCl}$.

15. Slide-A-Lyzer Dialysis Cassettes.

16. $0.22 \mu \mathrm{m}$ filters.

17. CspA Storage buffer: $10 \mathrm{mM}$ Tris- $\mathrm{HCl} \mathrm{pH} 8,1 \mathrm{mM}$ EDTA, $50 \mathrm{mM}$ potassium chloride and $10 \%$ glycerol.

18. Bio-Rad protein assay.

19. 96-well standard plates.

20. MultiSkan EX (Labsystems) or any other equivalent microplate photometer.

2.2 Assessment of the RNA Chaperone Activity with a Molecular Beacon
1. Molecular beacon mimicking the hairpin structure under study ( see Note 3).

2. Spectrophotometer equipped with a UV lamp (e.g., NanoDrop).

3. Recombinant RNA chaperone CspA (or protein of interest).

4. Bovine Serum Albumin (BSA) dissolved in CspA storage buffer at the same concentration as the protein of interest (see Note $4)$.

5. TE buffer: $10 \mathrm{mM}$ Tris- $\mathrm{HCl} \mathrm{pH} 7.5$ and $1 \mathrm{mM}$ EDTA.

6. 96-well PCR plates suitable for the Real-Time PCR System available. Plate is sealed with optically clear adhesive film (see Note 5).

7. AriaMx Real-Time PCR System (Agilent Technologies) or any other equivalent thermal cycler including an optical system able to excite the FAM fluorophore and register the fluorescence emission at different temperature incubation times. 
8. CspA storage buffer (see item 17 in Subheading 2.1.3).

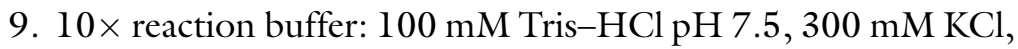
$200 \mathrm{mM} \mathrm{NH}_{4} \mathrm{Cl}, 15 \mathrm{mM}$ DTT, $50 \mathrm{mM} \mathrm{MgCl}_{2}$ (see Note 6 ).

10. $4 \mathrm{U} / \mu \mathrm{L}$ Ribolock (see Note 7 ).

11. Proteinase K (Sigma) stock solution. Dissolved Proteinase K powder in water to a final concentration of $20 \mathrm{mg} / \mathrm{mL}($ see Note 8 ). Store at $-20^{\circ} \mathrm{C}$.

\section{Methods}

\subsection{Purification of the Recombinant RNA Chaperone CspA}

3.1.1 Growth of Bacteria Expressing the GST-CspA Fusion Protein

3.1.2 Bacterial Cell Lysis and Recovery of Total Protein Crude Extract
1. Streak the E. coli BL21 (DE3) pGEX-6P-2::cspA strain in an $\mathrm{LB}$ agar plate supplemented with $100 \mu \mathrm{g} / \mathrm{mL}$ ampicillin and incubate at $37^{\circ} \mathrm{C}$ overnight.

2. Inoculate a colony of the previous culture into a sterile test tube containing LB medium supplemented with $100 \mu \mathrm{g} / \mathrm{mL}$ ampicillin and $1 \%$ glucose. Grow culture at $37^{\circ} \mathrm{C}$ and 200 r.p.m. overnight.

3. Inoculate $500 \mu \mathrm{L}$ of the bacterial preculture (1/1000 dilution factor) into two sterile pre-warmed 2-L Erlenmeyer flasks containing $500 \mathrm{~mL}$ of LB medium supplemented with $100 \mu \mathrm{g} / \mathrm{mL}$ ampicillin and $1 \%$ glucose. Mix and incubate the cultures at $37^{\circ} \mathrm{C}$ and 200 r.p.m. until an optical density $\left(\mathrm{OD}_{600 \mathrm{~nm}}\right)$ of 0.5 is reached.

4. Induce the expression of CspA by addition of IPTG to a final concentration of $0.4 \mathrm{mM}$. Save $1 \mathrm{~mL}$ of culture of one of the flasks and centrifuge it for $3 \mathrm{~min}$ at $18,000 \times g$. Store the bacterial pellet at $-20{ }^{\circ} \mathrm{C}$. This aliquot sample corresponds to the pre-induction control (see Note 9). Resume bacterial growth for another $5 \mathrm{~h}$ at $37^{\circ} \mathrm{C}$ and 200 r.p.m.

5. Save $1 \mathrm{~mL}$ of culture of one of the flasks and centrifuge it for $3 \mathrm{~min}$ at $18,000 \times \mathrm{g}$. Store the bacterial pellet at $-20^{\circ} \mathrm{C}$ (postinduction control) ( see Note 9). Harvest the rest of the cultures in $250-\mathrm{mL}$ tubes and centrifuge for $10 \mathrm{~min}$ at $5000 \times g(s e e$ Note 10). Discard the supernatant and resuspend the pellets in 1 volume of $\mathrm{PBS} \mathrm{pH}$ 7.3. Repeat the centrifugation step, discard the supernatant and store the bacterial pellets at $-80{ }^{\circ} \mathrm{C}(\operatorname{see}$ Note 11$)$.

1. Thaw the bacterial pellets, resuspend them in $25 \mathrm{~mL}$ PBS pH 7.3 in 50-mL conical tubes (per pellet) and add lysozyme, RNase and PSMF to a final concentration of $1 \mathrm{mg} / \mathrm{mL}, 10 \mu \mathrm{g} /$ $\mathrm{mL}$, and $1 \mathrm{mM}$, respectively. Incubate the samples for $30 \mathrm{~min}$ at $30{ }^{\circ} \mathrm{C}$ and 200 r.p.m. 
2. Sonicate the samples on ice as follows: 3 cycles of $30 \mathrm{~s}$ power 4,2 cycles of $30 \mathrm{~s}$ power 5 . Leave the samples on ice for $1 \mathrm{~min}$ in between cycles.

3. Centrifuge the samples at $16,000 \times g$ for $30 \mathrm{~min}$ at $4{ }^{\circ} \mathrm{C}($ see Note 10). Transfer the supernatant (soluble fraction) to new tubes and store the pellet at $-20^{\circ} \mathrm{C}$. Pellets (insoluble fraction) contain inclusion bodies (IB), and constitute the IB control (see Note 9).

4. Supplement the soluble fraction with DNase I and RNase A to a final concentration of $10 \mu \mathrm{g} / \mathrm{mL}$ and $5 \mu \mathrm{g} / \mathrm{mL}$, respectively, and incubate on ice for $30 \mathrm{~min}$. Store $50 \mu \mathrm{L}$ of the sample at $-20{ }^{\circ} \mathrm{C}$ (pre-filtered soluble fraction control) (see Note 9).

5. Filter the soluble fraction using a $0.45 \mu \mathrm{m}$ filter whilst on ice (see Note 12). Store $50 \mu \mathrm{L}$ of the sample at $-20{ }^{\circ} \mathrm{C}$ (postfiltered soluble fraction control) and the rest of the soluble fraction at $-20{ }^{\circ} \mathrm{C}$ ( see Note 9$)$.

6. Mix aliquots of the different control samples (pre-induction control, post-induction control, IB control, pre-filtered soluble fraction and post-filtered soluble fraction), collected in the previous steps (see Note 9 ), with $6 \times$ sample buffer to a final concentration of $1 \times$. Denature mixtures at $95^{\circ} \mathrm{C}$ for $5 \mathrm{~min}$ and load them in a polyacrylamide gel (a Molecular Weight Marker should be included) (see Note 13). Run the gel with $1 \times$ running buffer at $130 \mathrm{~V}$ until the front reaches the bottom of the gel ( see Note 14).

7. Stain the gel with Coomassie blue for at least $4 \mathrm{~h}$ at room temperature on an orbital shaker. Destain the gel with several washes of destaining solution at room temperature and shaking. Once protein bands are visible and the background level is low, incubate the gel with fixing solution for $15 \mathrm{~min}$ at room temperature and shaking. Optimal results are reached when most of the GST-CspA fusion protein appears in the soluble fraction and not in the inclusion bodies fraction ( see Note 15).

3.1.3 Purification of the Recombinant CspA Protein
1. Thaw the post-filtered soluble fraction and purify the GST-CspA fusion protein with the use of a GSTrap FF $5-\mathrm{mL}$ column and an AKTAprime plus chromatography system, following the recommendations of the manufacturer.

2. Clean the system with $20 \%$ ethanol and ultrapure water.

3. Connect the column to the AKTAprime plus system "drop to drop" to avoid introducing air into the column. Equilibrate the column with $25 \mathrm{~mL}$ of binding buffer at a flow rate of $5 \mathrm{~mL} /$ $\min$.

4. Apply the sample at a flow rate of $0.2 \mathrm{~mL} / \mathrm{min}($ see Note 16). 
5. Wash the column with $50 \mathrm{~mL}$ of binding buffer at a flow rate of $5 \mathrm{~mL} / \mathrm{min}$.

6. Equilibrate the column with $50 \mathrm{~mL}$ of PreScission Protease buffer at a flow rate of $5 \mathrm{~mL} / \mathrm{min}$ and disconnect the column from the AKTAprime plus chromatography system.

7. Prepare the PreScission Protease mix at $4{ }^{\circ} \mathrm{C}$ and load it manually onto the column using a syringe at a flow rate of $1 \mathrm{~mL} /$ min. Seal the column with the top and bottom stop plugs and incubate overnight at $4{ }^{\circ} \mathrm{C}$.

8. Connect a GSTrap FF 1-mL column to the AKTAprime plus system and equilibrate it with $5 \mathrm{~mL}$ of PreScission Protease buffer at a flow rate of $1 \mathrm{~mL} / \mathrm{min}$.

9. Place the GSTrap FF 5-mL column on top of the GSTrap FF 1-mL column. This tandem column scheme acts as a filter to capture any released cleaved GST proteins, uncleaved GST-tagged proteins and unbound PreScission Protease. Elute CspA with $15 \mathrm{~mL}$ of PreScission Protease buffer at a flow rate of $1 \mathrm{~mL} / \mathrm{min}$. Collect $1 \mathrm{~mL}$ fractions containing the CspA protein and place them on ice.

10. Elute the GST and GST-PreScission Protease from the columns with $30 \mathrm{~mL}$ of elution buffer at a flow rate of $1 \mathrm{~mL} /$ min. Clean the system and columns with ultrapure water and $20 \%$ ethanol and remove columns from the system.

11. Dialyze the CspA fractions against Gel Filtration buffer using a Slide-A-Lyzer Dialysis Cassette overnight at $4{ }^{\circ} \mathrm{C}$. Collect CspA from the Dialysis Cassette and filter the solution using a $0.22 \mu \mathrm{m}$ filter. Keep the CspA sample on ice until its purification by size exclusion chromatography.

12. Connect a HiPrep 16/60 Sephacryl S-100 HR Column (see Note 17) to the AKTAprime plus system "drop to drop" to avoid introducing air into the column. Equilibrate the column with $60 \mathrm{~mL}$ of ultrapure water at a flow rate of $0.5 \mathrm{~mL} / \mathrm{min}$ and then with $240 \mathrm{~mL}$ of Gel Filtration buffer at a flow rate of $1 \mathrm{~mL} / \mathrm{min}$.

13. Inject the CspA sample into the column and run it with $120 \mathrm{~mL}$ of Gel Filtration buffer at a flow rate of $0.5 \mathrm{~mL} /$ min. Collect $3 \mathrm{~mL}$ fractions and place them on ice.

14. Clean the column with $480 \mathrm{~mL}$ of ultrapure water and $480 \mathrm{~mL}$ of $20 \%$ ethanol at a flow rate of $1 \mathrm{~mL} / \mathrm{min}$. Remove the column from the system and clean the system with ultrapure water and $20 \%$ ethanol.

15. To select fractions containing CspA, mix an aliquot of each peak fraction with sample buffer $6 \times$ and perform a $12 \%$ PAGE as described above. 
16. Load the CspA selected fractions into a Slide-A-Lyzer Dialysis Cassette and dialyze against CspA Storage buffer overnight at $4{ }^{\circ} \mathrm{C}$.

17. To assess protein purity, mix an aliquot of the recombinant CspA chaperone with sample buffer $6 \times$ and perform a $12 \%$ SDS-polyacrylamide gel electrophoresis (PAGE) as described above.

18. Determine the recombinant protein concentration by the Bio-Rad protein assay.

\subsection{Assessment of the RNA Chaperone Activity with a Molecular Beacon}

3.2.1 Molecular Beacon Design

\subsubsection{Testing the Effectiveness of the Designed MB and Setup of the Working Conditions}

The success of this assay lies in an adequate MB design, which is based on two main principles: (1) the presence of an RNA structure targeted by the RNA chaperone under study and (2) fluorescence quenching exerted by a quencher dye (e.g., BHQ_l) on a fluorophore (e.g., FAM), which occurs when both molecules are in close proximity to one another. Additionally, the selected RNA structure must keep the quencher close enough to the fluorophore at the working temperature (switch OFF). MB mimicking hairpin-like structures have been shown to comply these criteria before [7-9]. Likewise, alternative $\mathrm{MB}$ conformations can be tested according to the characteristics of the protein of interest. Having decided the MB configuration, the synthesis of the labelled probe may be ordered to any oligonucleotide supplier (see Note 18). Based on the binding capacity of the CspA protein and the stability and cost of the probe, we decided to use single-stranded DNA instead of RNA oligonucleotides (see Note 19).

Before assessing if the RNA chaperone is able to unwind the MB structure, the effectiveness of the designed MB must be tested following two main criteria. On the one hand, no fluorescence emission should be detected when the MB is in an OFF state. On the other hand, maximum fluorescence levels should be registered when the $\mathrm{MB}$ is completely unfolded (ON state). In other words, a $\mathrm{MB}$ design will be appropriate when a large $\mathrm{ON} / \mathrm{OFF}$ fluorescence ratio is detected. Incubating different $\mathrm{MB}$ concentrations at increasing temperatures (that denature the oligonucleotide and open the structure leading to FAM fluorescence emission) helps determining both the background fluorescence (see Note 20) and the lowest quantity of oligonucleotide needed to obtain good fluorescence levels when the MB is in an ON state (see Note 21). To test if the MB design was successful, proceed as follows:

1. Dissolve the MB in TE buffer to obtain a concentration of $100 \mu \mathrm{M}$, following the manufacturer recommendations (see Note 22). Concentration of the MB should be corroborated with a spectrophotometer (e.g., NanoDrop). 
Table 1

Preparation of dilution mixes for testing MB effectiveness ${ }^{a}$

\begin{tabular}{lllllllll}
\hline & \multicolumn{9}{l}{ MB concentration (pmol) } & & & & & \\
\cline { 2 - 9 } & $\mathbf{0}$ & $\mathbf{0 . 5}$ & $\mathbf{1}$ & $\mathbf{2}$ & $\mathbf{5}$ & $\mathbf{1 0}$ & $\mathbf{1 5}$ & $\mathbf{2 0}$ \\
\hline MB 10 $\mathrm{M}$ & - & - & - & - & 0.5 & 1 & 1.5 & 2 \\
\hline MB I $\mu \mathrm{M}$ & - & 0.5 & 1 & 2 & - & - & - & - \\
\hline CspA storage buffer & 12.5 & 12 & 11.5 & 10.5 & 12 & 11.5 & 11 & 10.5 \\
\hline $10 \times$ reaction buffer & 2.5 & 2.5 & 2.5 & 2.5 & 2.5 & 2.5 & 2.5 & 2.5 \\
\hline Ultrapure water & 10 & 10 & 10 & 10 & 10 & 10 & 10 & 10 \\
\hline Final volume & $25 \mu \mathrm{L}$ & & & & & & & \\
\hline
\end{tabular}

${ }^{\mathrm{a}}$ Volumes of each reactive are indicated in $\mu \mathrm{L}$

${ }^{\mathrm{b}}$ Since the CspA protein is diluted in CspA storage buffer, the MB effectiveness test is performed including this buffer

2. Program the AriaMx thermal cycler to incubate the MB samples as follows: $37^{\circ} \mathrm{C}, 5 \mathrm{~min} ; 45^{\circ} \mathrm{C}, 5 \mathrm{~min} ; 55^{\circ} \mathrm{C}, 5 \mathrm{~min}$; and $65{ }^{\circ} \mathrm{C}$ during $5 \mathrm{~min}$ ( see Note 23). Register the emission of FAM fluorescence every minute.

3. Make serial dilutions of the MB in an optical 96-well plate as indicated in Table 1, which shows mixtures of the components to analyze different concentrations of the MB. Triplicates are highly recommended.

4. Seal the plate with an optically clear adhesive film (see Note 5) and load it into the thermal cycler. Start the incubation program.

5. Once the incubation time is finished, plot the obtained fluorescence signals in function of the MB concentration at the different temperatures. If replicates are used, plot the means of the fluorescence signals. The instrument background signal should be previously subtracted. Figure 4 shows an example of the results obtained with the $\mathrm{MB}$ designed for the analysis of S. aureus CspA activity [9] (Fig. 4). In this example, when the $\mathrm{MB}$ was incubated at $55^{\circ} \mathrm{C}$ and $65{ }^{\circ} \mathrm{C}$, fluorescence emission was registered, indicating that the $\mathrm{MB}$ was in an $\mathrm{ON}$ state. These fluorescence levels were directly proportional to the $\mathrm{MB}$ concentration. In contrast, when the $\mathrm{MB}$ was incubated at $37^{\circ} \mathrm{C}$ and $45^{\circ} \mathrm{C}$, the fluorescence values were close to those of the background confirming that the $\mathrm{MB}$ was in an OFF configuration. This experiment validated the functionality of the designed MB (see Note 24). 


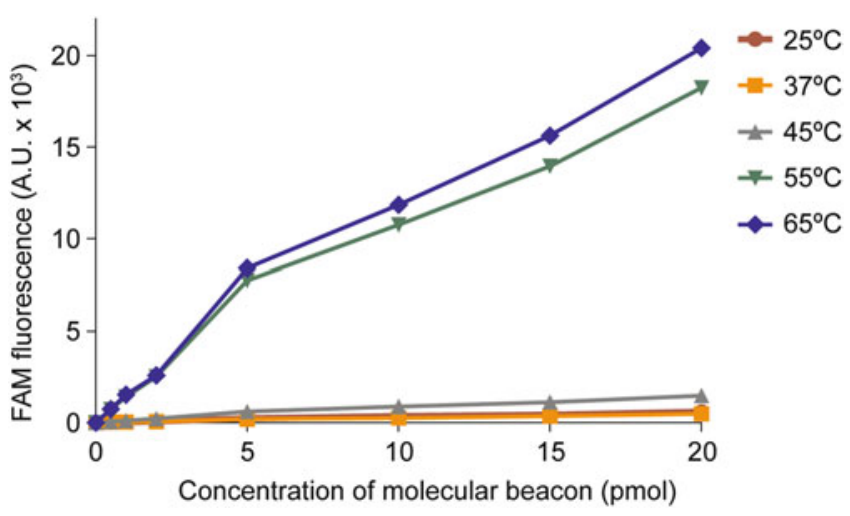

Fig. 4 Test of the molecular beacon functionality. Different concentrations of the $\mathrm{MB}$ mimicking the hairpin structure located at the $5^{\prime} \mathrm{UTR}$ of the $\operatorname{cspA}$ mRNA were incubated at different temperatures and fluorescence emission was registered. The experiment was carried out using the AriaMx thermal cycler

3.2.3 Determination of the RNA Chaperone Activity Using the Designed $M B$
1. Based on the data obtained from the MB effectiveness test, select the lowest $\mathrm{MB}$ concentration that gives a good ratio between the fluorescence and background signals (see Note 21).

2. Program the AriaMx thermal cycler to incubate the MB samples as follows: $37^{\circ} \mathrm{C}, 5 \mathrm{~min}$; PAUSE, $37^{\circ} \mathrm{C}$, $15 \mathrm{~min}$; PAUSE, $37^{\circ} \mathrm{C}, 30 \mathrm{~min} ; 65^{\circ} \mathrm{C}, 10 \mathrm{~min}$; STOP (Table 2). Register the fluorescence emission every minute (see Note 25 ).

3. Prepare an optical 96 -well plate including the reaction mixes as indicated in Table 2 (see Note 26). Note that the CspA and BSA proteins should be added later.

4. Seal the plate with adhesive film (see Note 5) and load it into the thermal cycler. Start the incubation program.

5. At the first pause of the incubation program, pull out the 96-well plate from the thermal cycler, remove the adhesive film and add the appropriate quantity of CspA and BSA. Re-seal the plate with a new adhesive film. This step must be performed swiftly.

6. Reintroduce the plate into the thermal cycler and continue the incubation at $37^{\circ} \mathrm{C}$ during $15 \mathrm{~min}$. Register the fluorescence emission every minute.

7. During the second incubation pause, pull out the plate, remove the adhesive film and add $10 \mu \mathrm{L}$ of proteinase $\mathrm{K}(20 \mathrm{mg} / \mathrm{mL})$. Re-seal the plate with a new adhesive film. This step must be performed swiftly.

8. Reintroduce the plate into the thermal cycler and continue the incubation for $30 \mathrm{~min}$ at $37^{\circ} \mathrm{C}$ and then increase the temperature up to $65^{\circ} \mathrm{C}$ during $10 \mathrm{~min}$. Register fluorescence emission 
Table 2

Determination of RNA chaperone activity: preparation of reaction mixes ${ }^{a}$

\begin{tabular}{|c|c|c|c|c|c|c|c|c|}
\hline & \multicolumn{8}{|c|}{ Samples $^{\text {b }}$} \\
\hline & 1 & 2 & 3 & 4 & 5 & 6 & 7 & 8 \\
\hline MB tube labelling & - & + & + & + & + & + & + & + \\
\hline CspA tube labelling & - & - & + & + & + & - & - & - \\
\hline BSA tube labelling & - & - & - & - & - & + & + & + \\
\hline Water (Vf: $100 \mu \mathrm{L}$ ) & 39 & 38 & 38 & 38 & 38 & 38 & 38 & 38 \\
\hline CspA storage buffer & 50 & 50 & 30 & 15 & - & 30 & 15 & - \\
\hline $10 \times$ reaction buffer & 10 & 10 & 10 & 10 & 10 & 10 & 10 & 10 \\
\hline $\mathrm{MB} \perp \mu \mathrm{M}$ & - & 1 & 1 & 1 & 1 & 1 & 1 & 1 \\
\hline \multirow[t]{5}{*}{ Ribolock $4 \mathrm{U} / \mu \mathrm{L}$} & 1 & 1 & 1 & 1 & 1 & 1 & 1 & 1 \\
\hline & \multicolumn{8}{|c|}{ Seal the plate with adhesive film } \\
\hline & \multicolumn{8}{|c|}{ Incubate $37^{\circ} \mathrm{C}-5 \mathrm{~min}$} \\
\hline & \multicolumn{8}{|c|}{ Register fluorescence emission every minute } \\
\hline & \multicolumn{8}{|c|}{ PAUSE incubation program ${ }^{\mathrm{c}}$} \\
\hline CspA stock $(\sim 200 \mu \mathrm{M})$ & - & - & 20 & 35 & 50 & - & - & - \\
\hline \multirow[t]{5}{*}{ BSA stock $(\sim 200 \mu \mathrm{M})$} & - & - & - & - & - & 20 & 35 & 50 \\
\hline & \multicolumn{8}{|c|}{ Re-seal the plate with adhesive film } \\
\hline & \multicolumn{8}{|c|}{ Incubate $37^{\circ} \mathrm{C}-15 \mathrm{~min}$} \\
\hline & \multicolumn{8}{|c|}{ Register fluorescence emission every minute } \\
\hline & \multicolumn{8}{|c|}{ PAUSE incubation program } \\
\hline \multirow[t]{7}{*}{ Proteinase $\mathrm{K} 20 \mathrm{mg} / \mathrm{mL}$} & 10 & 10 & 10 & 10 & 10 & 10 & 10 & 10 \\
\hline & \multicolumn{8}{|c|}{ Re-seal the plate with adhesive film } \\
\hline & \multicolumn{8}{|c|}{ Incubate $37^{\circ} \mathrm{C}-30 \mathrm{~min}$} \\
\hline & \multicolumn{8}{|c|}{ Incubate $65^{\circ} \mathrm{C}-10 \mathrm{~min}$} \\
\hline & \multicolumn{8}{|c|}{ Register fluorescence emission every minute } \\
\hline & \multicolumn{8}{|c|}{ Collect the fluorescence data from AriaMx thermal cycler } \\
\hline & \multicolumn{8}{|c|}{ Plot the data accordingly } \\
\hline
\end{tabular}

${ }^{\mathrm{a}}$ Volumes of each reactive are indicated in $\mu \mathrm{L}$

${ }^{b}$ Replicates of samples should be included

'If the thermal cycler software allows it, the entire incubation protocol can be pre-programed including the corresponding PAUSE times 
every minute. Once the incubation program is finished, collect the result data sheet.

9. Plot the obtained data subtracting the background fluorescence levels. If the experiments work as expected, fluorescence emission should be registered after addition of the RNA chaperone. This fluorescence should disappear after treatment with Proteinase $\mathrm{K}$, showing the specificity of the reaction. Finally, increasing the temperature at $65{ }^{\circ} \mathrm{C}$ should lead to maximum levels of fluorescence, indicating that the $\mathrm{MB}$ remains functional through the course of the experiment. Logically, in the negative controls, no fluorescence emission should be detected until the last step, when temperature is raised (e.g., see ref. 9).

\section{Notes}

1. Although we purified the RNA chaperone CspA from E. coli using the glutathione $S$-transferase (GST) gene fusion system, any other recombinant purification alternative can be used for your protein of interest. We fused the $\operatorname{csp} A$ coding sequence to the GST gene in the pGEX-6P-2 plasmid. This allowed the convenient site-specific cleavage by the PreScission Protease between the GST domain and CspA at low temperature, minimizing the degradation of the protein of interest. Additionally, it provided the recovery of the recombinant CspA protein with only a few extra amino acids in its sequence (for details about the construction of this strain see ref. 9). The fact that the PreScission Protease was engineered with a GST tag, permitted an on-column cleavage so that the GST moiety of the tagged protein and the PreScission Protease itself remained bound to the Glutathione Sepharose column. Thus, at the end of the procedure CspA was not contaminated with the protease.

2. PMSF is unstable in the presence of water. A stock solution should be prepared in anhydrous isopropanol or anhydrous absolute ethanol.

3. Our designed MB consisted of a 49-mer single-stranded DNA oligonucleotide, which was synthetized and labelled at its extremes with the 6-FAM molecule and Black Hole Quencher (BHQ_l) by the Integrated DNA technologies company. This length was enough to include the functional part of the RNA hairpin (Fig. 2).

4. We used bovine serum albumin (BSA), a protein without capacity to bind nucleic acids, as a negative control. Any alternative protein lacking DNA/RNA binding domains can also be used. 
5. We preferred to seal the 96-well plates with adhesive film because removing it and re-sealing the plates is faster than using flat caps. A quick sealing helps registering fluorescence emission sooner, after the RNA chaperone is added to the MB solution.

6. Storage of the $10 \times$ reaction buffer will require it to be prepared without DTT. DTT should be added just before use.

7. Any alternative RNase inhibitor can be used. If ssDNA is used as the backbone of the $\mathrm{MB}, \mathrm{RNase}$ inhibitors are not required.

8. To demonstrate the specificity of chaperone activity, proteinase $\mathrm{K}$ (or any alternative protease) may be included to degrade the protein under study. This should eliminate the RNA chaperone activity and restore the $\mathrm{MB}$ folding. If fluorescence is not quenched again after Proteinase K treatment (in other words, the $\mathrm{MB}$ cannot be refolded), it might indicate a contamination of the RNA chaperone solution with nucleases that affect the $\mathrm{MB}$ integrity.

9. It is important to collect samples at various steps during the purification procedure to monitor the yield of the recombinant protein. Comparison of these control samples helps evaluating if $(1)$ the induction of the recombinant protein expression is adequate (pre-induction vs post-induction control), (2) the recombinant protein is present in the soluble and/or the insoluble fraction (IB control vs soluble fractions), and (3) the recombinant protein is lost during the step of sample clearance by filtration (pre-filtered vs post-filtered soluble fractions).

10. Centrifuge should be pre-cooled before use.

11. Bacterial pellets can be stored at $-80{ }^{\circ} \mathrm{C}$ for several days.

12. We recommend the use of filters with a pore size of $0.45 \mu \mathrm{m}$ instead of $0.2 \mu \mathrm{m}$ to avoid filter saturation.

13. Pre-cast or custom-made gels may be used with the appropriate percentage of acrylamide according to the protein of interest (we used 12\% PAGE).

14. Adjust voltage of the electrophoresis system accordingly.

15. If the protein of interest is not in the soluble fraction, bacterial growing conditions should be modified to force its solubilization. Alternatively, protein purification methods from inclusion bodies may be applied.

16. Due to the slow binding kinetics between GST and glutathione, it is very important to keep the flow rate as low as possible during sample application for maximum binding capacity.

17. The column used in this protocol is specific for separating proteins with a small size. If the RNA chaperone of interest has a bigger size, the column should be changed accordingly. 
18. Some oligonucleotide supplier companies limit the synthesis of labelled oligonucleotide probes to 50 nucleotides (nt). In our design, the functional RNA hairpin region could be included in an oligonucleotide probe smaller than $50 \mathrm{nt}$. For larger regulatory structures, the synthesis of a $\mathrm{MB}$ may prove more challenging. This problem could be solved by dividing the MB synthesis into two shorter oligomers that can afterwards be ligated as previously described [7].

19. The reason for using a labelled DNA oligonucleotide as a MB is that it has been proven that CSPs can bind ssDNA as efficiently as RNA molecules [11]. Nevertheless, testing other RNA-binding proteins may require synthesis of RNA-based MBs.

20. If the region of the RNA structure under study is not strong enough to maintain the MB beacon in an OFF state, the basal level of fluorescence might be too high to obtain reliable results once the RNA chaperone is added.

21. Sometimes the quantity or the concentration of the chaperone under study can be limited. We recommend using the lowest concentration of the MB that gives good fluorescent levels in an ON state. This will help saving RNA chaperone sample.

22. The fluorophores of the MB are sensitive to the light; therefore, keep the stock and any other dilutions wrapped in aluminum foil and protect them from exposure to light to maintain their integrity.

23. The selected temperature might vary depending on the melting temperature of the $\mathrm{MB}$ structure.

24. If the control of the MB functionality does not show clear differences on the fluorescence signals between ON and OFF states, and/or the fluorescence background is too high, the MB should be redesigned.

25. The entire incubation protocol to be carried out with the AriaMx thermal cycler (or any equivalent equipment) can be programed from the beginning, including the corresponding pause times required to add the different components of the reactions.

26. Volumes of each reactive should be adjusted according to the concentration of the RNA chaperone.

\section{Acknowledgments}

We thank Prof. Iñigo Lasa for critical reading of the manuscript. This work was supported by the European Research Council (ERC) under the European Union's Horizon 2020 research and innovation program (Grant Agreement No. 646869) and the Spanish 
Ministry of Economy and Competitiveness (BFU2014-56698-P). C.J.C. was supported by a predoctoral contract from the Public University of Navarre (UPNA), Spain.

\section{References}

1. Tan W, Wang K, Drake TJ (2004) Molecular beacons. Curr Opin Chem Biol 8:547-553

2. Marx A, Seitz O (2010) Molecular beacons: signalling nucleic acid probes, methods, and protocols. Humana Press, Totowa

3. Li J, Cao ZC, Tang Z et al (2008) Molecular beacons for protein-DNA interaction studies. Methods Mol Biol 429:209-224

4. Li JJ, Geyer R, Tan W (2000) Using molecular beacons as a sensitive fluorescence assay for enzymatic cleavage of single-stranded DNA. Nucleic Acids Res 28:E52

5. Hopkins JF, Woodson SA (2005) Molecular beacons as probes of RNA unfolding under native conditions. Nucleic Acids Res 33:5763-5770

6. Chinnappan R, Dubé A, Lemay J-F et al (2013) Fluorescence monitoring of riboswitch transcription regulation using a dual molecular beacon assay. Nucleic Acids Res 41:e106

7. Phadtare S, Inouye M, Severinov K (2002) The nucleic acid melting activity of Escherichia coli
CspE is critical for transcription antitermination and cold acclimation of cells. J Biol Chem 277:7239-7245

8. Kuehnert J, Sommer G, Zierk AW et al (2015) Novel RNA chaperone domain of RNA-binding protein La is regulated by AKT phosphorylation. Nucleic Acids Res 43:581-594

9. Caballero CJ, Menendez-Gil P, CatalanMoreno A et al (2018) The regulon of the RNA chaperone CspA and its auto-regulation in Staphylococcus aureus. Nucleic Acids Res 46:1345-1361

10. Lioliou E, Sharma CM, Caldelari I et al (2012) Global regulatory functions of the Staphylococcus aureus endoribonuclease III in gene expression. PLoS Genet 8:e1002782

11. Phadtare S, Inouye M (1999) Sequenceselective interactions with RNA by $\mathrm{CspB}$, CspC and CspE, members of the CspA family of Escherichia coli. Mol Microbiol 33:1004-1014

Open Access This chapter is licensed under the terms of the Creative Commons Attribution 4.0 International License (http://creativecommons.org/licenses/by/4.0/), which permits use, sharing, adaptation, distribution and reproduction in any medium or format, as long as you give appropriate credit to the original author(s) and the source, provide a link to the Creative Commons license and indicate if changes were made.

The images or other third party material in this chapter are included in the chapter's Creative Commons license, unless indicated otherwise in a credit line to the material. If material is not included in the chapter's Creative Commons license and your intended use is not permitted by statutory regulation or exceeds the permitted use, you will need to obtain permission directly from the copyright holder. 